\title{
Characteristic transformation of humic acid during photoelectrocatalysis process and its subsequent disinfection byproduct formation potential
}

\author{
Angzhen $\mathrm{Li}^{a, b}, \mathrm{Xu} \mathrm{Zhao}^{a}$, Huijuan Liu ${ }^{a}$, Jiuhui $\mathrm{Qu}{ }^{a, *}$ \\ a State key Laboratory of Environmental Aquatic Chemistry, Research Center for Eco-Environmental Sciences, Chinese Academy of Sciences, \\ Beijing 100085, China \\ ${ }^{\mathrm{b}}$ Graduate School, Chinese Academy of Sciences, Beijing 100039, China
}

\section{A R T I C L E I N F O}

Article history:

Received 11 May 2011

Received in revised form

4 September 2011

Accepted 5 September 2011

Available online 14 September 2011

Keywords:

Photoelectrocatalytic process

Humic acid

Disinfection byproduct formation potential

Structure variation

Functional groups

\begin{abstract}
A B S T R A C T
In this study, degradation of humic acid (HA) via photoelectrocatalysis (PEC) process and corresponding disinfection byproduct formation potential (DBPFP) were investigated. Particularly, structure variation and subsequent DBPFP of HA during PEC treatment were correlated. The PEC process was found to be effective in reducing dissolved organic carbon concentration by $75.0 \%$ and UV absorbance at $254 \mathrm{~nm}$ by $92.0 \%$. Furthermore, $90.3 \%$ of haloacetic acids formation potential and $89.8 \%$ of trihalomethanes formation potential were reduced within $180 \mathrm{~min}$. Based on molecular weight and resin fraction results, it was demonstrated that HA with large aromatic, hydrophobic and long aliphatic chain organics were transformed into small and hydrophilic organics during PEC process. Combined with the fourier transform infrared spectra and ${ }^{13} \mathrm{C}$ nuclear magnetic resonance spectra analysis of HA fractions, it was concluded that phenolic hydroxyl and conjugated double bonds tended to be attacked by hydroxyl radicals during PEC process; these groups were reactive with chlorine to produce disinfection byproducts (DBP), especially trihalomethane and trichloroacetic acid. By contrast, amino, carboxyl and alcoholic hydroxyl groups were relatively difficult to be oxidized during PEC process; these groups had the potential to form dichloroacetic acid during chlorination. Results of these studies confirmed that PEC process was a safe and effective technique to decrease DBP formation significantly in water treatment plant.
\end{abstract}

() 2011 Elsevier Ltd. All rights reserved.

\section{Introduction}

Humic acid (HA) is the major fraction of natural organic matter in water, which poses significant concerns to water utility and can interfere with several water treatment processes (Chen et al., 1977). It is known that HA can react with oxidants to produce small molecular organic substances, which contribute to producing halogenated disinfection byproducts (DBP) during chlorination. In particular, HA is the principal precursor of trihalomethanes (THMs) and haloacetic acids (HAAs), which are potentially carcinogenic (Nie et al., 2010; Xue et al., 2011). Therefore, it is important to understand the characteristic transformation of HA during the oxidation process and establish potential alternative water treatment processes to reduce DBP precursors.

Coagulation and activated carbon adsorption are commonly used to remove HA from water (Bond et al., 2010). It is frequently found that these treatment processes are limited

\footnotetext{
* Corresponding author. Tel.: +86 10 62849151; fax: +86 1062923558.

E-mail addresses: jhqu@mail.rcees.ac.cn, jhqu@rcees.ac.cn (J. Qu). 0043-1354/\$ - see front matter @ 2011 Elsevier Ltd. All rights reserved. doi:10.1016/j.watres.2011.09.012
} 
in the removal of HA with low molecular weight fraction. Recently, application of advanced oxidation processes (AOPs) in $\mathrm{HA}$ removal, such as $\mathrm{UV} / \mathrm{H}_{2} \mathrm{O}_{2}$ and $\mathrm{TiO}_{2} / \mathrm{UV}$ has gained momentum (Sanly et al., 2008a, b; Siva and Madjid, 2010). The AOPs are attractive due to the potential of free radicals to degrade the organic macromolecules (Sanly et al., 2008a, b). By contrast with other AOPs, it is easier to remove DBP precursors during photocatalysis (PC) process before disinfection. However, the problems of $\mathrm{TiO}_{2}$ separation from aqueous phase and fast recombination rate of electron-hole pair become the limitation of PC treatment (Sanly et al., 2008a, b).

One way to improve the performance of immobilized $\mathrm{TiO}_{2}$ is to fix the catalyst on a conductive substrate and apply external voltage to a photoelectrochemical cell, thus driving the photo-generated electrons to the cathode and, consequently, minimizing the rate of electron/hole recombination. The process, which is also referred to as photoelectrocatalysis (PEC), has successfully demonstrated the degradation of HA (Kim and Anderson, 1994; Li et al., 2002; Pinhedo et al., 2005; Huseyin and Miray, 2008; Huseyin, 2010). Previous studies on the PEC oxidation of HA focused on the effect of treatment parameters, such as $\mathrm{pH}$, external potential, and HA dose on the removal efficiency (Pinhedo et al., 2005). In addition, these studies used bulk parameters, such as DOC analysis and UV spectrophotometry to assess treatment performance (Kim and Anderson, 1994; Li et al., 2002; Huseyin and Miray, 2008; Huseyin, 2010). However, these parameters may not be adequate to fully elucidate the chemical process. Relatively little information was available on how PEC process changed the composition and characteristics of HA. Furthermore, in consideration of drinking water security it is important to know the potential of the treated water to form DBP.

In this study, the evolution of HA and decrease of disinfection byproduct formation potential (DBPFP) during the PEC treatment were fully investigated. HA was fractionated by ultrafiltration and resin fractionation according to the molecular weight and physicochemical properties (Aiken et al., 1992; Leenheer et al., 2000; Kitis et al., 2002; Hua and Reckhow, 2007). Each organic fraction and its speciation variation during PEC process were examined for their associated functional groups by three dimensional excitationemission matrix (3DEEM) fluorescence, fourier transform infrared (FT-IR) and ${ }^{13} \mathrm{C}$ nuclear magnetic resonance $\left({ }^{13} \mathrm{C} N \mathrm{NR}\right)$ spectra analysis. Correlation of HA structure variation with corresponding DBPFP of HA during PEC process was also investigated.

\section{Materials and methods}

\subsection{HA and fractionation}

Commercially sourced HA from Aldrich was used. HA stock solution was prepared by mixing $4 \mathrm{~g}$ of $\mathrm{HA}$ in $1 \mathrm{~L}$ of $0.1 \mathrm{M}$ sodium hydroxide (Univar) over a period of $1 \mathrm{~d}$ and then filtered through $0.45 \mu \mathrm{m}$ glass fiber membrane filters and stored in the dark at $4{ }^{\circ} \mathrm{C}$.

Diluted HA was fractionated into five fractions using a stirred ultrafiltration cell device(Model 8200, Amicon, Millipore) with nominal molecular weight cutoffs of $3,10,30$, and
$100 \mathrm{kDa}$ regenerated cellulose membranes (PL, $63.5 \mathrm{~mm}$, Millipore). Experimental details follow the procedure done by Kitis et al. (2002). Meanwhile, diluted HA was also fractionated by resin fractionation. The filtered HA was acidified to $\mathrm{pH} 2$ using $6 \mathrm{M}$ sulfuric acid and then passed through DAX-8 resin followed by XAD-4 resin, in accordance with the method of Aiken et al. (1992). Effluent from the XAD-4 resin was collected, which was referred to as the hydrophilic (Hi) fraction. The hydrophobic (Ho) and transphilic (Hs) fractions were retained by DAX- 8 and XAD- 4 resin respectively, and these were eluted with $0.1 \mathrm{M}$ sodium hydroxide in the reverse direction. The Ho and Hs fractions were re-concentrated on the appropriate resin and hydrogen-saturated using Dowex Marathon MSC-H cation exchange resin obtained from $\mathrm{J}_{\&} \mathrm{~K}$. The dissolved organic carbon (DOC) concentration and the UV absorbance at $254 \mathrm{~nm}\left(\mathrm{UV}_{254}\right)$ of each HA fraction were measured.

\subsection{Reactor setup and degradation experiments of HA}

Electrochemical oxidation (EO), PC, and PEC processes for HA degradation were carried out in a $600 \mathrm{~mL}$, singlecompartment, air-tight glass cell with a $3.5 \mathrm{~cm}$-diameter quartz tube placed in the center and used as the UV bulb housing. UV irradiation was provided by a $10 \mathrm{~W}$-pressure mercury lamp $(253.7 \mathrm{~nm})$ and the light intensity at the center of the compartment was $1.36 \mathrm{~mW} \mathrm{~cm} \mathrm{~cm}^{-2}$ as measured with a UV radiometer (Light and Electric instruments Factory of Beijing Normal University). The experimental setup was described by Xiao et al. (2009). The reactor was controlled by a DC power supply source AMERLLPS302A (Dahua instrument corporation of Beijing). The $\mathrm{TiO}_{2} / \mathrm{Ti}$ film electrode (100 $\mathrm{mm} \times 60 \mathrm{~mm} \times 2 \mathrm{~mm}$, Hengli Ti Corporation of Beijing) was selected as anode with an apparent surface area of $60 \mathrm{~cm}^{2}$, and $\mathrm{TiO}_{2}$ films were deposited onto the Ti plate via a dip-coating method as described by shang et al. (2003). $\mathrm{RuO}_{2} / \mathrm{Ti}$ electrode with the same solid surface area was selected as cathode.

\subsection{DBP formation potential}

A $24 \mathrm{~h}$ chlorination DBPs test of raw HA and treated water samples were carried out according to Standard Method 5710 with modifies (Greenberg et al., 1995). The sodium hypochlorite $(\mathrm{NaOCl})$ stock solution with the concentration of $20 \mathrm{mg}$ $\mathrm{Cl}_{2} / \mathrm{mL}$ was stored in an aluminum foil-covered glass stopped flask. Chlorine dosing solution was prepared from the dilution of $\mathrm{NaOCl}$ stock solution (about $5 \mathrm{mg} \mathrm{Cl} / \mathrm{mL}$ ). Sodium hydroxide/potassium dihydrogen phosphate $\left(\mathrm{NaOH} / \mathrm{KH}_{2} \mathrm{PO}_{4}\right)$ buffer solutions ( $\mathrm{pH}$ 7.0) and chlorine dosing solution were injected into each sample. The chlorine dose was determined by $4 \mathrm{~h}$ preliminary demand tests on each sample according to Standard Method 5710B (Greenberg et al., 1995). After being dosed with chlorine, samples were stored headspace-free at $25 \pm 2{ }^{\circ} \mathrm{C}$ in the dark for $24 \mathrm{~h}$. All samples were found to have measurable free chlorine residuals by an N,N-diethyl-pphenylenediamine (DPD) titrimetric method (Clesceri et al., 1998). According to the chlorine dose, water samples were then added with sodium sulfite to quench the residual free chlorine and analyzed to determine the concentrations of 
trihalomethane formation potential (THMFP) and haloacetic acid formation potential (HAAFP) (Li et al., 2008).

Four THMs $\left(\mathrm{CHCl}_{3}, \mathrm{CHBrCl}_{2}, \mathrm{CHBr}_{2} \mathrm{Cl}, \mathrm{CHBr}_{3}\right)$ samples were extracted with hexane (HPLC Grade, Fisher, USA) and measured following the U.S EPA Method 551 (U.S.EPA, 1990). Nine HAAs (monochloro-, monobromo-, dichloro-, bromochloro-, dibromo-, bromodichloro-, bromodichloro-, dibromochloro-, trichloro- and tribromoacetic acid) samples were extracted with methyl-tert-butyl ether (MTBE) (HPLC Grade, J.T. Baker, USA) followed by derivation with acidic methanol according to the U.S. EPA Method 552.3 (U.S.EPA, 1990). 1,2dibromopropane ( $\geq 98.0 \%$, GC, Fluka, USA) was used as the internal standard. Conditions for the analyses were as follows: (1) THMs, injector temperature $200{ }^{\circ} \mathrm{C}$, column temperature $35^{\circ} \mathrm{C}$ (holding $\left.4 \mathrm{~min}\right)$ to $260^{\circ} \mathrm{C}\left(10^{\circ} \mathrm{C} / \mathrm{min}\right)$, detector temperature $290{ }^{\circ} \mathrm{C}$; (2) HAAs, injector temperature $200{ }^{\circ} \mathrm{C}$, column temperature $35^{\circ} \mathrm{C}$ (holding $\left.4 \mathrm{~min}\right)$ to $65^{\circ} \mathrm{C}\left(2^{\circ} \mathrm{C} / \mathrm{min}\right)$, detector temperature $290^{\circ} \mathrm{C}$.

\subsection{Characterization of HA}

HA and each fraction powder obtained through freeze-drying were analyzed for their structural and chemical characteristics. $\mathrm{KBr}$ (FT-IR Grade, Aldrich Co., USA) was mixed with the HA powder at the ratio of 100 to 1 and the FT-IR spectra of the mixture was obtained with IR spectrometer (Thermo Nicolet 5700, USA).

3DEEM fluorescence spectra were recorded on a fluorescence spectrophotometer (model F-4500, Hitachi, Japan). 3DEEM spectra were obtained by measuring the emission spectra in the range from 280 to $550 \mathrm{~nm}$ repeatedly at the excitation wavelengths from 220 to $440 \mathrm{~nm}$. Blanks of ultrapure water were included in the correction of inner filtering and Raman scattering of the fluorescence spectra.

The solid-state ${ }^{13} \mathrm{C}$ NMR spectra were acquired using a cross polarization magic angle spinning (CPMAS) on a Bruker instrument (AVANCE III, $400 \mathrm{MHz}$, Bruker, Germany) with a $4 \mathrm{~mm} \mathrm{H} / \mathrm{X} / \mathrm{Y}$ probe. CPMAS ${ }^{13} \mathrm{C}$ NMR was performed on 100-200 mg of samples. The main experimental parameters included contact time of $3 \mathrm{~ms}$, pulse delay of $1 \mathrm{~s}$, spinning rate of $5000 \mathrm{~Hz}$ and 20480 scans per sample.

The PEC oxidation intermediates of HA were detected by gas chromatography/mass spectrometry (GC/MS) (Agilent 7890 GC-5975MSD) equipped with an HP-5 capillary column (30 m $\times 0.25 \mathrm{~mm}, 0.25 \mu \mathrm{m}$ film thickness). Details of GC/MS tests were included in the Supplementary Data.

\section{Results and discussion}

\subsection{PEC degradation of DBP precursors}

Degradation of HA, namely DBP precursors, was performed in the PC, EO and PEC process. Fig. 1 shows the DOC and $\mathrm{UV}_{254}$ removal efficiency of HA during $\mathrm{PC}, \mathrm{EC}$ and $\mathrm{PEC}$ process at $\mathrm{pH}$ 7. With an applied current density of $5 \mathrm{~mA} / \mathrm{cm}^{2}$, the removal efficiency of $\mathrm{UV}_{254}$ and DOC during PEC process was determined to be $92 \%$ and $75 \%$ within 180 min. By contrast, the removal efficiency of $\mathrm{UV}_{254}$ and DOC during PC process was $25 \%$ and $13 \%$, respectively; only $17 \%$ reduction of $U_{254}$ and $8 \%$

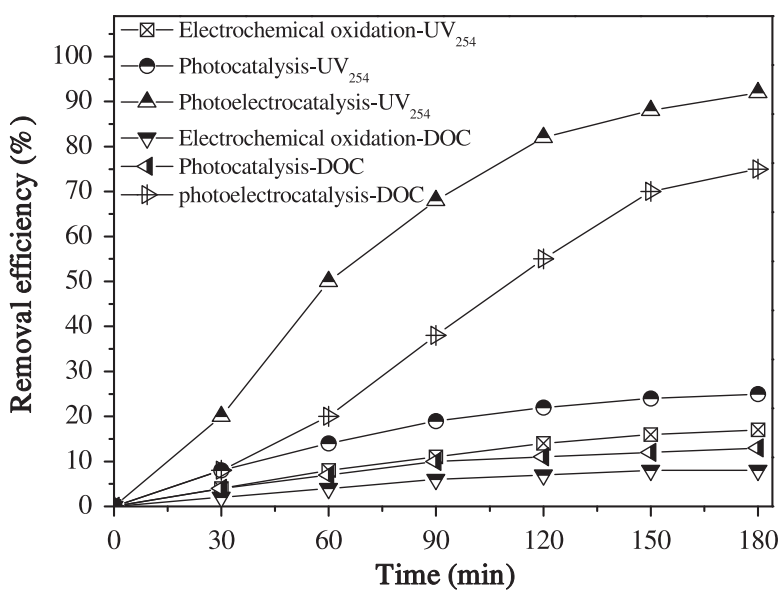

Fig. 1 - Performance of photocatalysis, electrochemical oxidation and photoelectrocatalysis process during humic acid degradation. (initial $\mathrm{pH}=7.0$, initial $\mathrm{DOC}=10.0 \mathrm{mg} / \mathrm{L}$ as $\mathrm{C}, \mathrm{Na}_{2} \mathrm{SO}_{4}=10.0 \mathrm{mmol} / \mathrm{L}$ ).

reduction of DOC were achieved during EO process. It was clear that significant synergetic effects occurred during PEC process. When a potential greater than the flat-band potential of the $\mathrm{TiO}_{2} / \mathrm{Ti}$ electrode was applied, the charge recombination process will be inhibited (Li et al., 2002; Pinhedo et al., 2005; Huseyin, 2010). Thus, the HA was efficiently degraded during PEC process.

Furthermore, it is clear seen from Fig. 1 that the removal of $\mathrm{UV}_{254}$ was preferred to the removal of DOC. Within $180 \mathrm{~min}$, approximately $2.5 \mathrm{mg} / \mathrm{L} \mathrm{DOC}$ still remained in the HA solution during PEC process. Even with prolonged reaction time, removal of DOC was limited. Higher percentage of $\mathrm{UV}_{254}$ removal compared to DOC removal indicated an incomplete mineralization of the organics after the breakup of large aromatic and conjugated structures. Similar results were also reported by Huang et al. (2008), who observed that a fraction of the DOC could not be removed completely, implying the presence of refractory compounds, either present in the beginning or generated during PC process.

\subsection{Characterization and variation of DBP precursors during PEC process}

\subsubsection{Variation of DBP precursors fractionation}

Raw HA and treated HA during PEC process were taken at given time and fractionated by ultrafiltration and resin fractionation according to molecular weight and physicochemical properties. The molecular weight distribution of samples taken during the PEC process are presented in Fig. 2(a). The fraction with molecular weight $>100 \mathrm{kDa}$ fraction dominated $78.4 \%$ of the DOC of raw $\mathrm{HA}$ at $\mathrm{pH}$ 7. Each of the other four fractions ( $<3 \mathrm{kDa}, 3-10 \mathrm{kDa}, 10-30 \mathrm{kDa}$ and $30-100 \mathrm{kDa}$ ) represented less than $6 \%$ of the DOC. However, the $>100$ and $<3 \mathrm{kDa}$ fraction comprised $2.6 \%$ and $67.2 \%$ of total DOC at $180 \mathrm{~min}$ during PEC process, respectively. These results revealed that the $\mathrm{PEC}$ oxidation preferentially degraded the large molecular weight fractions of HA, forming small 
a

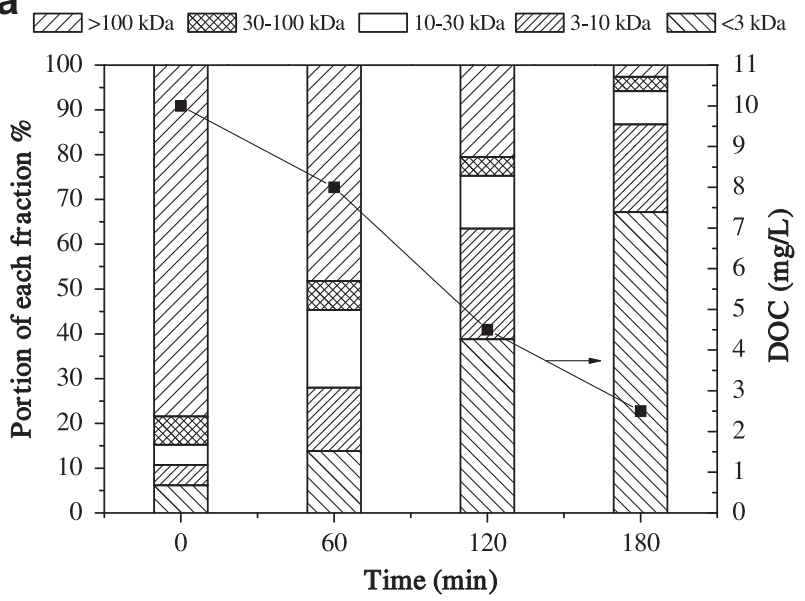

b

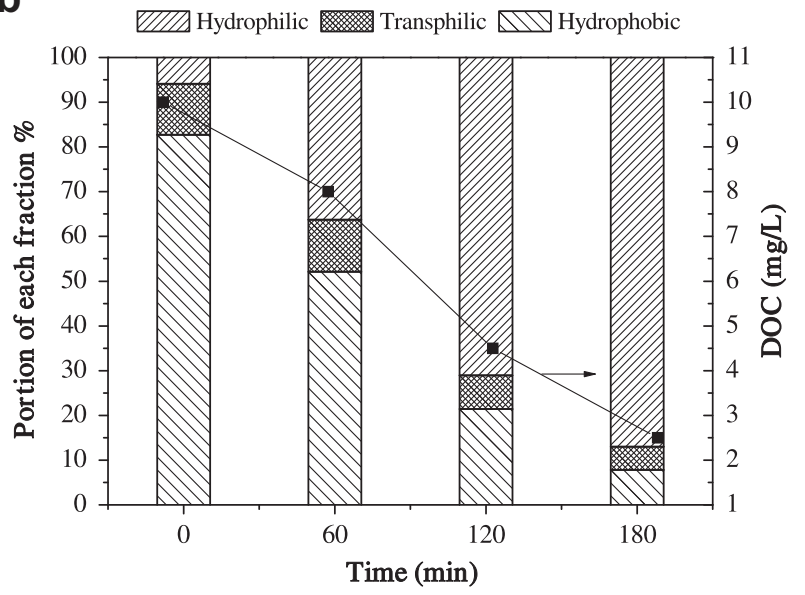

Fig. 2 - DOC concentration variation of the humic acid fractionation during photoelectrocatalysis process. (a) based on molecular size; (b) based on hydrophobicity. (initial DOC $=10.0 \mathrm{mg} / \mathrm{L}$ as $\mathrm{C}$, initial $\mathrm{pH}=7.0$, $\mathrm{Na}_{2} \mathrm{SO}_{4}=10.0 \mathrm{mmol} / \mathrm{L}$, current density $=5 \mathrm{~mA} / \mathrm{cm}^{2}$ ).

molecular weight fractions, which were subsequently degraded after the large molecular weight organics were nearly diminished.

Fig. 2(b) illustrates DOC variations of the three resin fractions of samples taken during PEC process at $\mathrm{pH}$ 7. The resin fractionation result indicated that the Ho fraction predominated the DOC composition of HA: $8.3 \mathrm{mg} / \mathrm{L}$ of Ho fraction (82.7\% of DOC), with the Hs and Hi fractions making up $1.1 \mathrm{mg} /$ L (11.4\% of DOC), and $0.6 \mathrm{mg} / \mathrm{L}$ (5.9\% of DOC), respectively. Within 180 min of PEC process, the overall DOC concentration of the Ho fraction and HA decreased by $8.1 \mathrm{mg} / \mathrm{L}$ and $7.5 \mathrm{mg} / \mathrm{L}$, respectively. The DOC concentration of the Hs fraction remained stable with $60 \mathrm{~min}$, and then decreased during PEC process. While Ho and Hs fractions continuously decreased following treatment, the DOC concentration of $\mathrm{Hi}$ fraction increased from $0.59 \mathrm{mg} / \mathrm{L}$ to $3.20 \mathrm{mg} / \mathrm{L}$ within $120 \mathrm{~min}$, and reduced to $2.18 \mathrm{mg} / \mathrm{L}$ at $180 \mathrm{~min}$. From calculations, it was found that the rate of Ho being converted to Hs/Hi was 2.3, 1.6, and 1.3 times faster than the rate of $\mathrm{Hs} / \mathrm{Hi}$ being degraded to carbon dioxide $\left(\mathrm{CO}_{2}\right)$ at $60 \mathrm{~min}, 120 \mathrm{~min}$, and $180 \mathrm{~min}$, respectively, which suggested that the Ho fraction was prone to PEC degradation. Thus, when the Ho fraction was almost completely degraded, the hydroxyl radicals (HO-) continued to attack the Hs and Hi fraction. This was also agreeable with the molecular weight results since the Ho fraction was composed of large molecular weight components, which were expected to be more readily degraded (Patrica et al., 2002). Tran et al. reported that the Ho fraction generally contained a large proportion of aromatic structures (Tran et al., 2006). It is known that aromatic compounds tend to have a high electron density and therefore an increased probability of being attacked by $\mathrm{HO} \cdot$. The $\mathrm{Hi}$ fraction contains more aliphatic carbon and nitrogenous compounds (such as carbohydrates, sugars, and amino acids), which are more difficult to be degraded than the Ho fraction (Hua and Reckhow, 2007). The results from this study indicated that HA degradation proceeded via breakup of large molecular weight and hydrophobic nonpolar fractions to form small molecular weight and hydrophilic charged fractions during PEC process.

\subsubsection{DEEM fluorescence spectroscopy analysis}

Detailed 3DEEM illumination for the HA fractions of $\mathrm{Ho}, \mathrm{Hs}$, and $\mathrm{Hi}$ is shown in Fig. 3. Excitation and emission boundaries were operationally defined into five regions based on the results by Wen et al. (2003). Additionally, $\mathrm{f}_{450 / 500}$ corresponded to the ratio of emission intensity at $450 \mathrm{~nm}$ over $500 \mathrm{~nm}$ at $370 \mathrm{~nm}$ excitation and lower $\mathrm{f}_{450 / 500}$ may refer to the compounds with more aromatic structures. The $\mathrm{f}_{450 / 500}$ for the Ho, Hs and Hi fraction was 1.13, 1.50 and 1.34, respectively. It is shown in Fig. 3 that the peak of Hi appeared in Region II; the peaks of Ho and Hs appeared in Region V. These peaks suggested that the Hi fraction contained protein-like substances, whereas the Ho and Hs fractions contained humic acid-like substances. Furthermore, the Ho fraction may have more aromatic sites than the other two fractions.

Fig. 4 shows the variation of HA fluorescence spectroscopy with the reaction time during PEC process. The fluorescence intensity of peak at 324/440 (excitation (Ex)/emission (Em) $(\mathrm{nm})$ ) in Region V decreased from 50 (a.u.) to 30 (a.u.) within $60 \mathrm{~min}$, then the peak in Region $\mathrm{V}$ almost disappeared at 180 min during PEC process. While a peak in the Region IV appeared at $180 \mathrm{~min}$, which indicated that the small molecular weight organics were formed during the reaction. Furthermore, the blue shift of the peak from 325/445 (excitation (Ex)/emission (Em) (nm)) to 324/440 (Ex/Em (nm)) within $60 \mathrm{~min}$ was observed. It is recognized that blue shift of $\mathrm{Ex} / \mathrm{Em}$ reflects the transformation of organic material into small molecular weight composition and a reduction in the degree of the $\pi$-electron system (Swietlika and Sikorska, 2004). The result suggested HA with the large molecular weight fraction was decomposed to small molecular weight fraction during PEC process. Moreover, because the breakup of aromatic structures were easily achieved, the Ho degradation was easier than the Hs and Ho fractions.

\subsubsection{FT-IR analysis}

The FT-IR spectra for $\mathrm{HA}$ and its fractions of $\mathrm{Ho}, \mathrm{Hi}$, and $\mathrm{Hs}$ are shown in Fig. 5 (a). As seen in Fig. 5(a), Ho was found to have a peak at $1645 \mathrm{~cm}^{-1}$, which indicates that Ho had more aromatic structures (Hyun and Myong, 2005; Elizabeth and Brandon, 
a

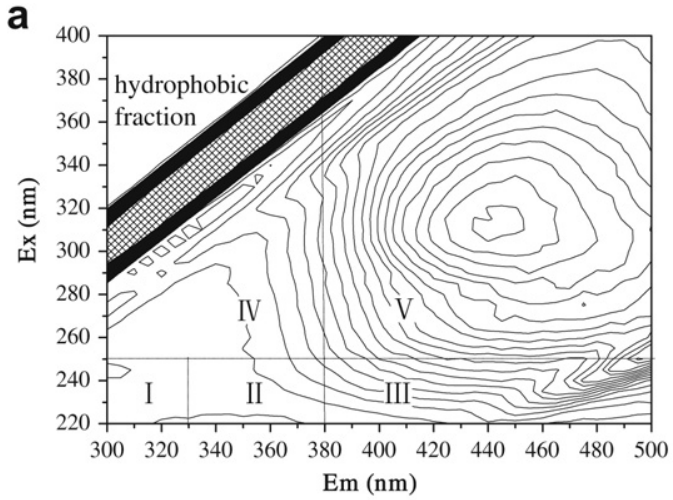

b

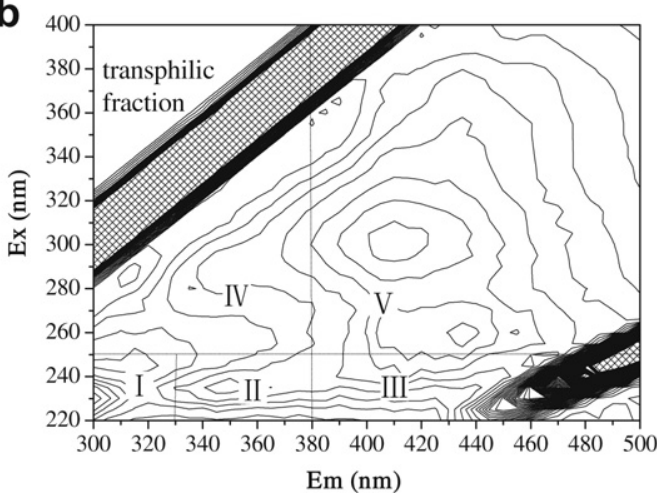

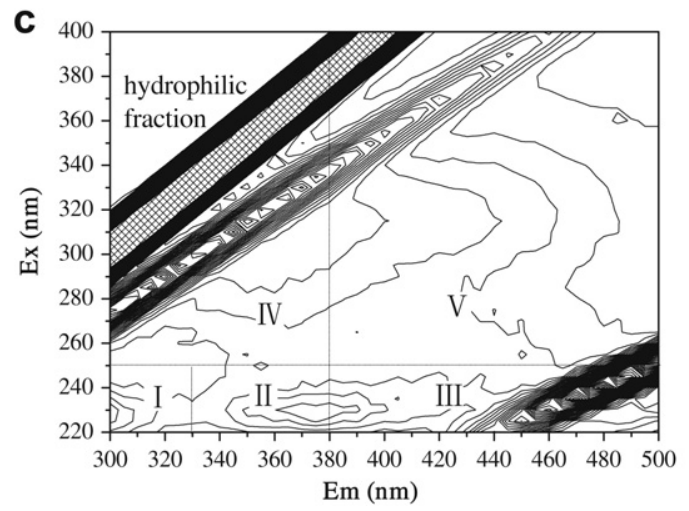

Fig. 3 - Fluorescene spectroscopy of humic acid fractions based on hydrophobicity. (a) Hydrophobic fraction; (b) transphilic fraction; (c) Hydrophilic fraction.

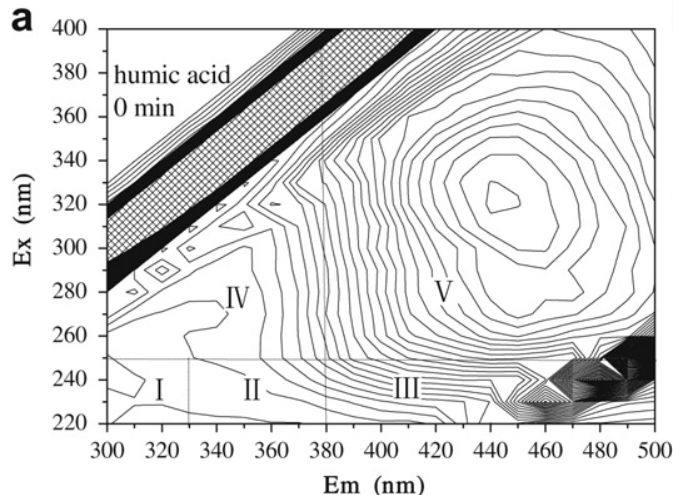

Em (nm) b 400

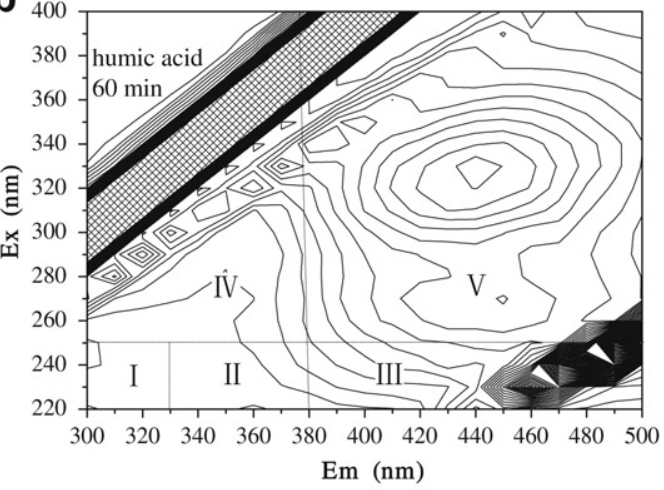

C

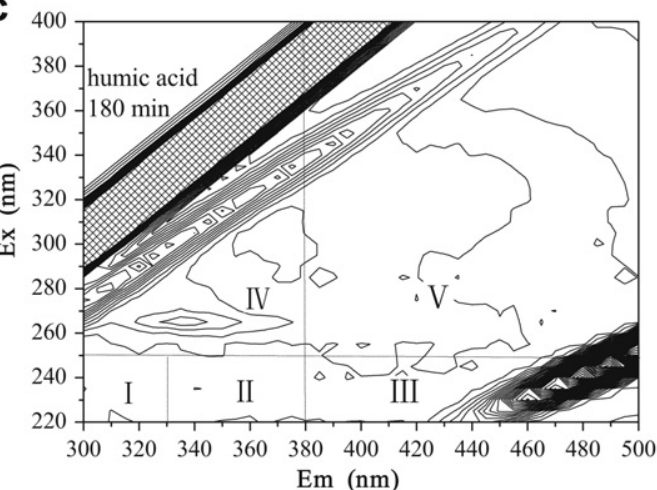

Fig. 4 - Fluorescene spectroscopy of humic acid during photoelectrocatalysis process. (a) 0 min; (b) $60 \mathrm{~min}$; (c) $180 \mathrm{~min}$ (initial DOC $=10.0 \mathrm{mg} / \mathrm{L}$ as $\mathrm{C}, \mathrm{Na}_{2} \mathrm{SO}_{4}=10.0 \mathrm{mmol} / \mathrm{L}$, current density $=5 \mathrm{~mA} / \mathrm{cm}^{2}$ ). 

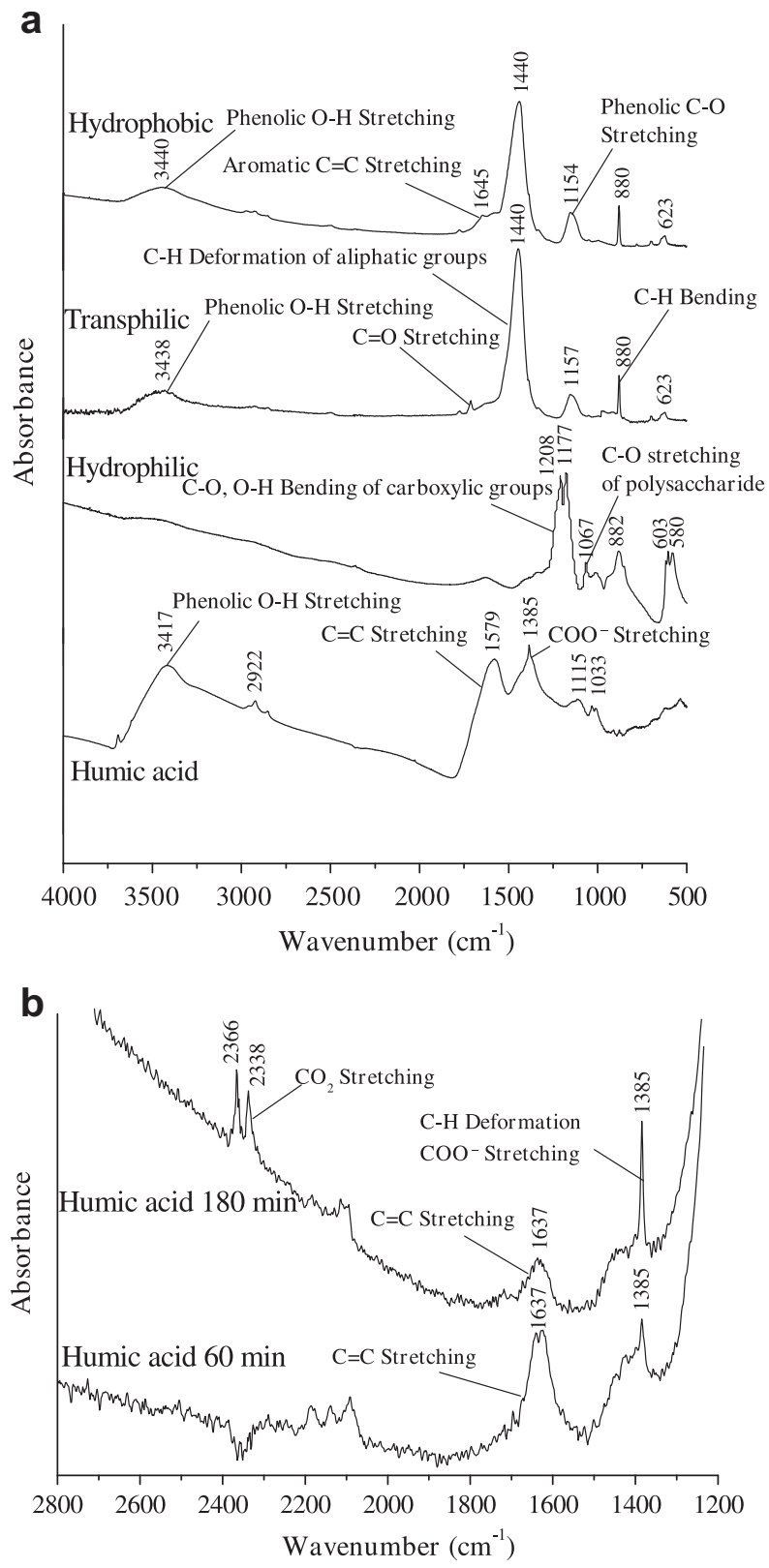

Fig. 5 - (a) FT-IR spectra of humic acid and fractions based on hydrophobicity; (b) FT-IR spectra of humic acid during photoelectrocatalysis process.

2008). Whereas Hs showed a peak at $1714 \mathrm{~cm}^{-1}$, which is attributed to carboxylic and carbonyl- $\mathrm{C}=\mathrm{O}$ stretching (Hyun and Myong, 2005). Ho and Hs were similar in spectra with a peak at around $3440 \mathrm{~cm}^{-1}, 1440 \mathrm{~cm}^{-1}$ and $880 \mathrm{~cm}^{-1}$, which refer to $\mathrm{O}-\mathrm{H}$ stretching from the presence of phenols, $\mathrm{C}-\mathrm{H}$ deformation of aliphatic groups and $\mathrm{C}-\mathrm{H}$ bending of the substituted aromatic groups, respectively (Valdemar et al., 2009). Compared with Ho and $\mathrm{Hs}$, Hi showed a peak at around $1628 \mathrm{~cm}^{-1}$, which corresponds to $\mathrm{N}-\mathrm{H}$ deformation and $\mathrm{C}=\mathrm{N}$ stretching of primary amides (Hyun and Myong, 2005). Additionally, Hi showed a peak at $1067 \mathrm{~cm}^{-1}$, which is assigned to $\mathrm{C}-\mathrm{O}$ stretching of polysaccharide or polysaccharide-like substances (Elizabeth and Brandon, 2008). Summarily, the Ho fraction mainly contained phenolic hydroxyl and conjugated double bonds while the Hs fraction contained more carbonyl. However, the Hi fraction may contain more amino, carboxyl and alcoholic hydroxyl groups.

The FT-IR spectra of HA during the PEC process is shown in Fig. 5 (b). The intense absorbance of $\mathrm{SO}_{4}^{2-}$ vibration in the $1200-$ $1000 \mathrm{~cm}^{-1}$ region covered up the vibration of some organic groups. Thus, the magnifying $2800-1200 \mathrm{~cm}^{-1}$ region was chosen for FT-IR result. As shown in Fig. 5 (b), the reaction samples taken at $60 \mathrm{~min}$ and $180 \mathrm{~min}$ showed peaks at $1385 \mathrm{~cm}^{-1}$ and $1637 \mathrm{~cm}^{-1}$, which are attributed to $\mathrm{C}-\mathrm{H}$ deformation in methyl, methylene groups and $\mathrm{C}=\mathrm{C}$ stretching vibration, respectively (Hyun and Myong, 2005; Elizabeth and Brandon, 2008). The peak intensity at $1637 \mathrm{~cm}^{-1}$ was stronger for the sample at $60 \mathrm{~min}$ than that at $180 \mathrm{~min}$; on the contrary, the peak at $1385 \mathrm{~cm}^{-1}$ was weaker for the sample at $60 \mathrm{~min}$ than that for $180 \mathrm{~min}$. While the reaction samples taken at $180 \mathrm{~min}$ also showed peaks at $2338 \mathrm{~cm}^{-1}$ and $2366 \mathrm{~cm}^{-1}$, which are attributed to $\mathrm{CO}_{2}$ stretching vibration (Valdemar et al., 2009). These peaks indicated that during PEC process aromatic sites were prone to attack by HO to form ring-opened products, such as carboxylic acid, and oxidation to $\mathrm{CO}_{2}$. Combined with resin fractionation results, it was concluded that PEC process primarily destroyed the aromatic and conjugated structure of HA and transformed large aromatic and long aliphatic chain organic structures to small and hydrophilic organics. Furthermore, the preferred removal of the Ho fraction revealed that phenolic hydroxyl and conjugated double bonds tended to be attacked by HO during PEC process. However, the slow degradation of the Hi fraction indicated that amino, carboxyl and alcoholic hydroxyl groups were relatively difficult to be oxidized during PEC process.

\subsubsection{CPMAS ${ }^{13} \mathrm{C}$ NMR analysis}

Raw HA and HA fractions of Ho and Hs were analyzed using the CPMAS ${ }^{13} \mathrm{C}$ NMR spectra. As shown in Fig. 6(a), HA and Ho fraction showed higher content of carbons with resonances in the range of 110-160 ppm than Hs fraction. Furthermore, HA samples taken during a given time were also presented in Fig. 6(b). It could be seen that the carbon resonance in the region $110-160$ ppm decreased notably within 180 min during the PEC process.

Previous studies indicated that the spectra were integrated into the following chemical shift regions: alkyl-C (0-50 ppm), O-alkyl-C (predominantly carbohydrates, 50-110 ppm), aromatic-C (110-160 ppm), carboxyl-C (160-190 ppm), and carbonyl-C (190-220 ppm) (Zhao et al., 2009). The relative intensity of these regions was determined by the integration of the corresponding peak areas. In addition, the aromaticity and aliphaticity of the samples were calculated according to Eq. (1) and Eq. (2):

Aromaticity $=C_{\hat{\delta}_{110-160}} / C_{\delta} \times 100 \%$

Aliphaticity $=C_{\delta_{0-110}} / C_{\delta} \times 100 \%$

Table 1 showed the relative intensity of functional groups for the HA fractions and samples taken during PEC process by CPMAS ${ }^{13} \mathrm{C}$ NMR spectra. HA and Ho fractions presented more intense resonances in aromatic carbon than Hs fraction. 


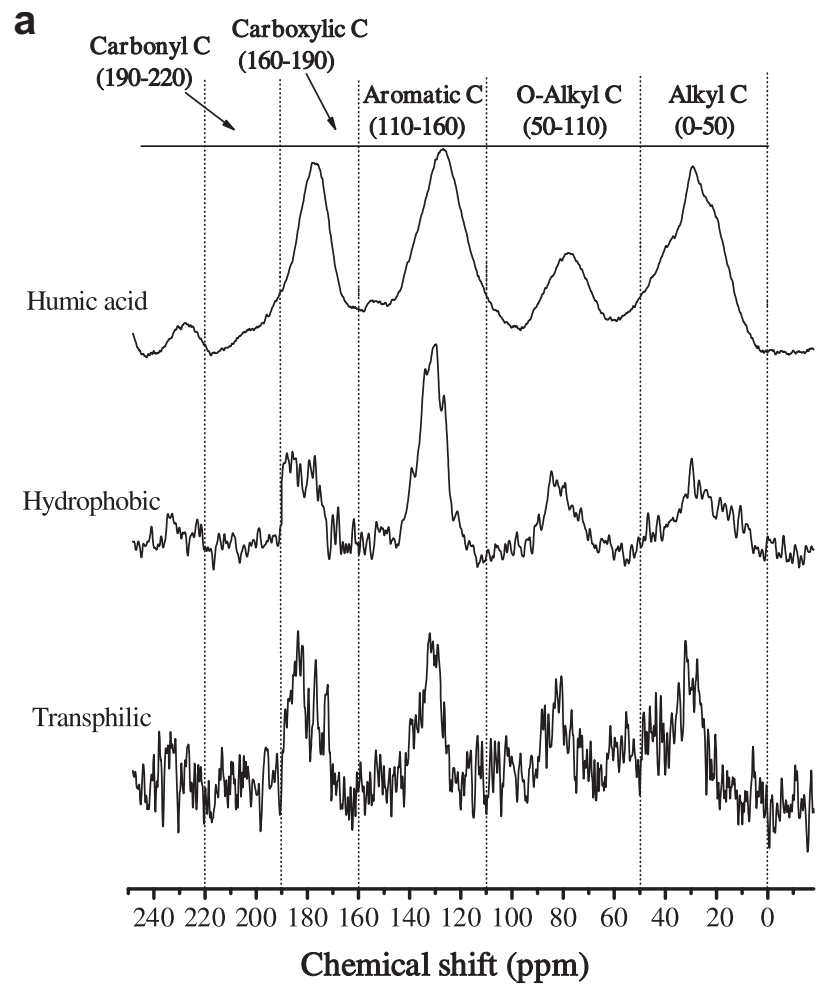

b

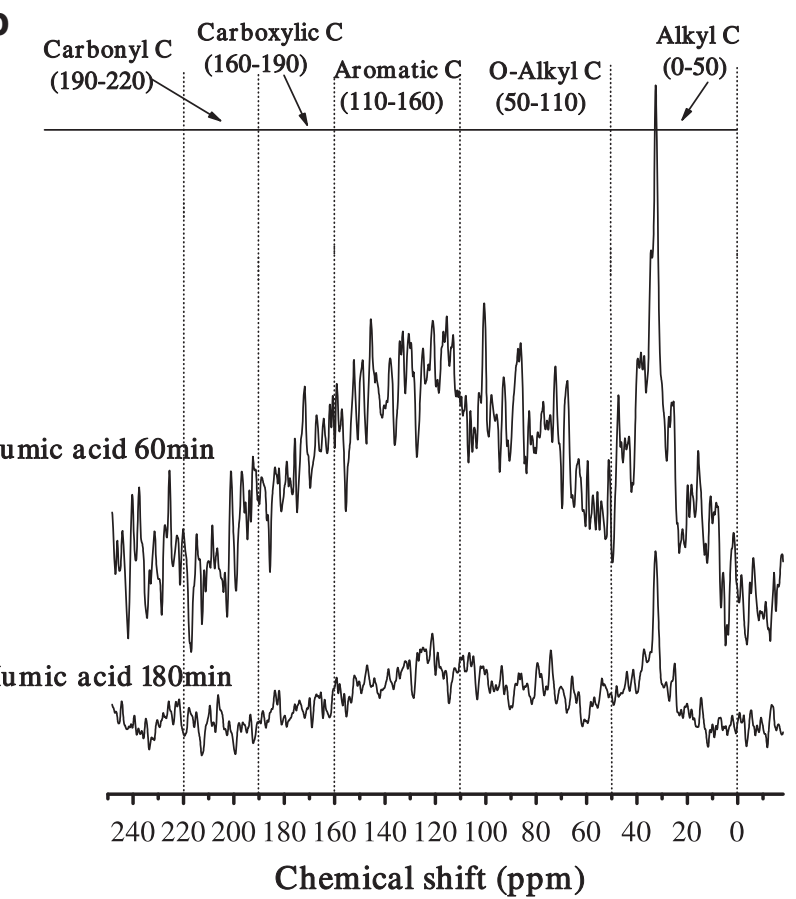

Fig. 6 - (a) ${ }^{13} \mathrm{C}$ NMR spectra of humic acid and fractions; (b) ${ }^{13} \mathrm{C}$ NMR spectra of humic acid during photoelectrocatalysis process. (initial $\mathrm{pH}=7.0$, $\mathrm{Na}_{2} \mathrm{SO}_{4}=10.0 \mathrm{mmol} / \mathrm{L}$, current density $\left.=5 \mathrm{~mA} / \mathrm{cm}^{2}\right)$.

However, the Hs fraction indicated higher aliphatic, carboxylic and carbonyl carbon intensity, as compared to the Ho fraction. Furthermore, Table 1 showed that the aromaticity for HA decreased from $40.13 \%$ to $19.47 \%$ within $180 \mathrm{~min}$, accompanied by the increase of carbohydrate carbon contents from $19.01 \%$ to $35.69 \%$. These results indicated that the aromatic structure of HA was destroyed whereas the oxygenated aliphatic structures increased during PEC process. These results indicated that the possible reactions between $\mathrm{HA}$ and $\mathrm{HO}$ involved the addition of HO to aromatic and conjugated structures, then further oxidation could yield alcohol, carboxylic acids, carbohydrates, which may be mineralized during PEC process. These findings were in agreement with the FT-IR analysis.

\subsubsection{GC/MS analysis}

Typical GC/MS chromatograms of HA during PEC process are illustrated in detail in the Supplementary Data (Table S1 and Figure S1). As shown in Figure S1, at $60 \mathrm{~min}$, intermediate of dibutyl phthalate was detected. At $180 \mathrm{~min}$, glyoxylic acid, dibutyl phthalate, hexadecanoic acid and octadecanoic acid were identified. It was reported that the oxidation of HA was accomplished by attacking the unsaturated moieties $\mathrm{C}=\mathrm{C}(\mathrm{Li}$ et al., 2008). As a result, such organics as ketones, alcohol, ester, ether, and carboxylic acids could be formed via HO. addition reactions to the unsaturated groups of HA (such as vinyl and aromatic groups) during PEC oxidation.

\subsection{DBPFP reduction and the correlations between the functional groups of DBP precursors}

The DBPFP of HA fractions were measured to assess the reactivity of intermediates with chlorine during PEC treatment. Fig. 7 (a) and (b) indicate that the distribution of four THMs, nine HAAs and the DBPFP/DOC value from three fractions (Ho, $\mathrm{Hs}$ and $\mathrm{Hi}$ ). However, the formation of $\mathrm{CHCl}_{3}$, dichloroacetic acid (DCAA) and trichloroacetic acid (TCAA) contributed to more than $90 \%$ of total DBPFP. It could be seen that Ho produced the highest value of THMFP/DOC (38.72 $\mu \mathrm{g} /$ $\mathrm{mg} \mathrm{C})$ and HAAFP/DOC (55.13 $\mu \mathrm{g} / \mathrm{mg} \mathrm{C})$ yields; Meanwhile, Ho exhibited the highest densities of $\mathrm{CHCl}_{3}$ (99.87\%) and trichloroacetic acid (TCAA) (64.09\%) in THMFP and HAAFP, whereas Hs produced almost equal densities of dichloroacetic acid (DCAA) (46.47\%) and TCAA (47.71\%). The Hi fraction produced more brominated trihalomethane (THM-Br) (19.61\%) and DCAA (63.36\%) in contrast to the other two fractions. However, THM-Br contributed less to the THMFP since the original HA samples had a low level of bromide $(<20 \mu \mathrm{g} / \mathrm{L})$. This suggests that THM and TCAA precursors were more hydrophobic, while hydrophilic fractions were important as DCAA precursors (Lin and Singer, 2003). Considering the FT-IR result of Ho and Hi fractions of HA, it could be deduced that phenolic hydroxyl and conjugated double bonds had high potential to produce THM and TCAA during chlorination. Whereas this FT-IR result also suggested that amino, carboxyl and alcoholic hydroxyl groups were prone to produce DCAA during chlorination.

Fig. 7 (c) and (d) revealed the variation of DBPFP and DBPFP/ DOC of HA fractions during PEC process. It was shown that the THMFP/DOC value decreased drastically from 35.14 to $17.14 \mu \mathrm{g} / \mathrm{mg} \mathrm{C}$ during PEC treatment. In contrast to THMFP/ DOC value, HAAFP/DOC value didn't decrease all the time. The little increase in the HAAFP/DOC value from $120 \mathrm{~min}$ to 180 min may be attributed to the increase in hydrophilic 
Table 1 - Characterization for HA fractions and intermediates during PEC process analyzed by ${ }^{13} \mathrm{C}$ NMR spectra.

Relative intensity of functional group (\%)

Alkyl 0-50 Carbohydrate 50-110 Aromatic 110-160 Carboxyl Carbonyl

$\begin{array}{llll}(\mathrm{ppm}) & (\mathrm{ppm}) & \text { 160-190 } & 190-220\end{array}$

\begin{tabular}{|c|c|c|c|c|c|c|c|}
\hline & $\begin{array}{l}\text { Alkyl 0-50 } \\
\text { (ppm) }\end{array}$ & $\begin{array}{l}\text { Carbohydrate } 50-110 \\
(\mathrm{ppm})\end{array}$ & $\begin{array}{l}\text { Aromatic } 110-160 \\
\text { (ppm) }\end{array}$ & $\begin{array}{c}\text { Carboxyl } \\
\text { 160-190 } \\
\text { (ppm) }\end{array}$ & $\begin{array}{c}\text { Carbonyl } \\
\text { 190-220 } \\
\text { (ppm) }\end{array}$ & $(\%)$ & \\
\hline Humic acid & 26.98 & 19.01 & 30.84 & 19.11 & 4.06 & 40.13 & 59.87 \\
\hline Hydrophobic & 21.58 & 11.79 & 47.53 & 18.35 & 0.75 & 58.75 & 41.25 \\
\hline Transphilic & 28.32 & 22.62 & 21.04 & 22.80 & 5.22 & 29.23 & 70.77 \\
\hline Humic acid $60 \mathrm{~min}$ & 20.99 & 26.41 & 28.61 & 19.33 & 4.66 & 37.64 & 62.36 \\
\hline Humic acid $180 \mathrm{~min}$ & 32.35 & 35.69 & 16.45 & 14.31 & 1.2 & 19.47 & 80.53 \\
\hline
\end{tabular}

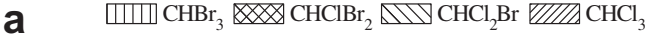
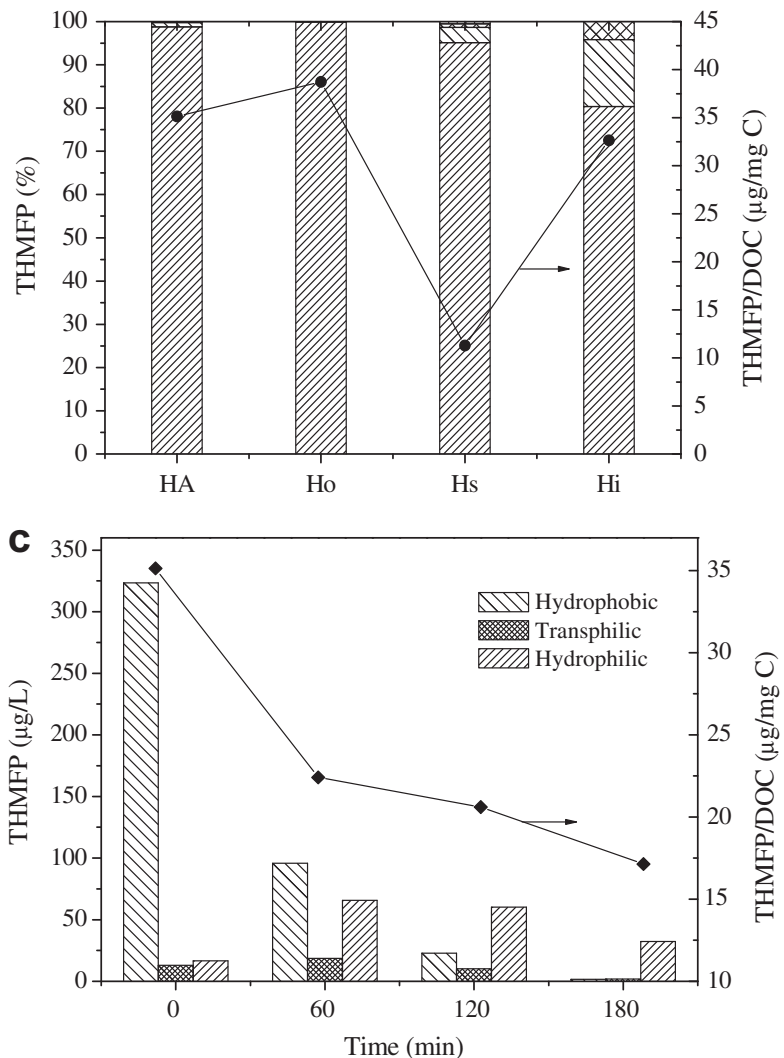

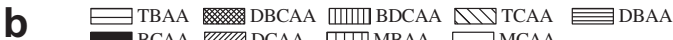

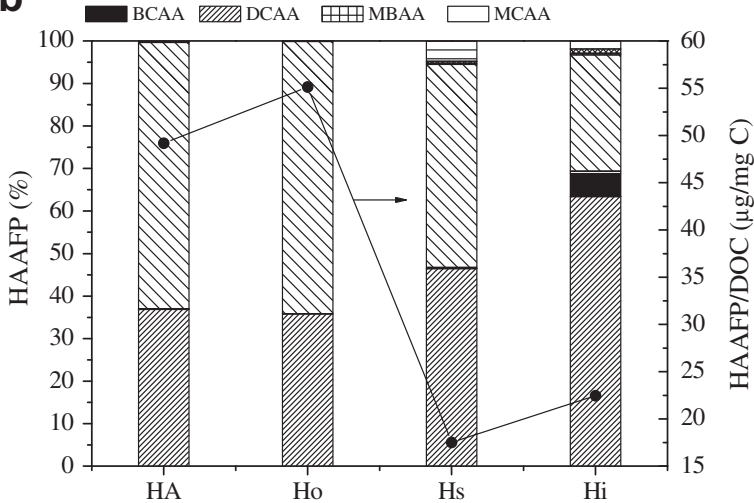

d

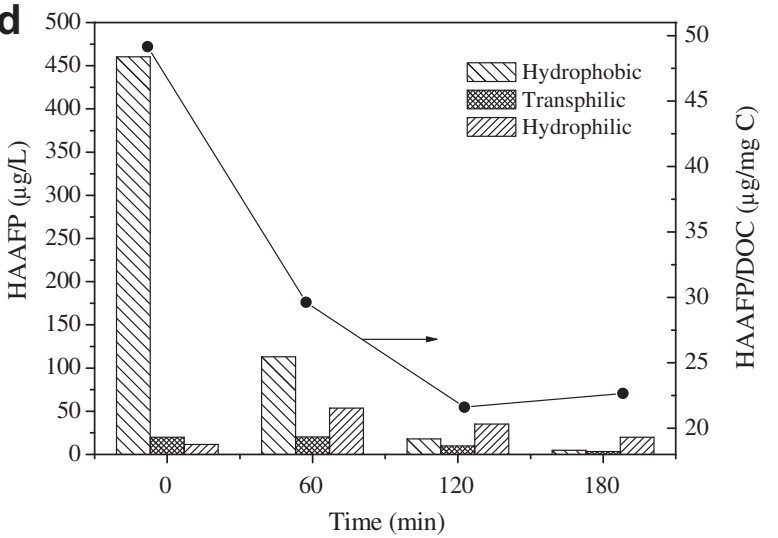

Fig. 7 - DBPFP and DBPFP/DOC value of humic acid based on resin fractionation during photoelectrocatalysis process. (a) Distribution of four THMs in chlorinated humic acid fractions; (b) distribution of nine HAAs in chlorinated humic acid fractions; (c) THMFP and THMFP/DOC of humic acid fractions during photoelectrocatalysis process; (d) HAAFP and HAAFP/ DOC of humic acid fractions during photoelectrocatalysis process. (initial DOC $=10.0 \mathrm{mg} / \mathrm{L} \mathrm{as} \mathrm{C,} \mathrm{Na}_{2} \mathrm{SO}_{4}=10.0 \mathrm{mmol} / \mathrm{L}$, applied potential $=8.0 \mathrm{~V}$ vs $\mathrm{SCE})$.

fraction during PEC process. PEC oxidation preferentially degraded DBPFP of Ho fraction; whereas, at the initial stage of the PEC oxidation, DBPFP of Hi fraction increased then proceeded to decrease at a slow rate. This was in accordance with the fractionation result that the PEC process broke up large molecular weight, hydrophobic nonpolar fractions to form small molecular weight, hydrophilic charged fractions. Accordingly, THM and TCAA precursors were significantly oxidized during PEC process; whereas, DCAA precursors were relatively stable during PEC process.

\section{Conclusions}

In summary, the photoelectrocatalysis process showed higher efficiency in removal of humic acid and capacity to decrease 
disinfection byproducts formation of humic acid than photocatalysis and electrochemical oxidation process. Humic acid was fractionated into three fractions, and the hydrophobic fraction mainly contained phenolic hydroxyl and conjugated double bonds; the transphilic fraction contained more carbonyl in contrast to the hydrophobic fraction. The hydrophilic fraction may contain more amino, carboxyl and alcoholic hydroxyl groups. It was demonstrated that hydrophobic fractions had the highest potential to produce trihalomethanes and haloacetic acids in contrast to the transphilic and hydrophilic fractions. Loss of aromaticity and conjugation was easier to achieve than mineralization of humic acid. Large aromatic and long aliphatic chain organic structures were transformed into small and hydrophilic organics during the photoelectrocatalysis process. These results indicated that phenolic hydroxyl and conjugated double bonds were primarily responsible for disinfection byproducts formation during chlorination, especially trihalomethane and trichloroacetic acid formation; amino and alcoholic hydroxyl groups were important precursors for dichloroacetic acis. It was concluded that the superiority of photoelectrocatalysis process for reducing trihalomethane and trichloroacetic acid precursors compared to dichloroacetic acis precursors.

\section{Acknowledgments}

This project is supported by Funds for the Creative Research Group of China (Grant 50921064), National Natural Science Foundation of China (Grant 50938004) and National Basic Research Program of China (2010CB933604). The kind suggestions from the editors and reviewers are deeply appreciated.

\section{Appendix. Supplementary material}

Supplementary data associated with this article can be found, in the online version, at doi:10.1016/j.watres.2011.09.012.

\section{R E F E R E N C E S}

Aiken, G.R., McKnight, D.M., Thorn, K.A., Thurman, E.M., 1992. Isolation of hydrophilic organic acids from water using nonionic macroporous resins. Organic Geochemistry 18 (4), 567-573.

Bond, T., Goslan, E.H., Parsons, S.A., Jefferson, B., 2010. Disinfection by-product formation of natural organic matter surrogates and treatment by coagulation, MIEX and nanofiltration. Water Research 44 (5), 1645-1653.

Chen, Y., Senesi, N., Schnitzer, M., 1977. Information provided on humic substances by $E_{4} / E_{6}$ ratios. Soil Science Society of America Journal 41 (2), 352-358.

Clesceri, L.S., Greenberg, A.E., Eaton, A.D., 1998. Standard Methods for the Examination of Water and Wastewater, twentieth ed.. American Public Health Association, American Water Works Association. 461-463.

Elizabeth, M., Brandon, S., 2008. Dissolved organic matter characteristics within the Lake Superior watershed. Organic Geochemistry 39 (11), 1489-1501.
Greenberg, A.E., Clesceri, L.S., Eaton, A.D., 1995. Standard Methods for the Examination of Water and Wastewater, nineteenth ed. American Public Health Association, Washington, DC.

Hua, G.H., Reckhow, D.A., 2007. Characterization of disinfection byproduct precursors based on hydrophobicity and molecular size. Environmental Science and Technology 41 (9), 3309-3315.

Huang, X., Leal, M., Li, Q., 2008. Degradation of natural organic matter by $\mathrm{TiO}_{2}$ photocatalytic oxidation and its effect on fouling of low-pressure membranes. Water Research 42 (4-5), $1142-1150$

Huseyin, S., 2010. Disinfection and formation of disinfection byproducts in a photoelectrocatalytic system. Water Research 44 (13), 3966-3972.

Huseyin, S., Miray, B., 2008. Photocatalytic and photoelectrocatalytic humic acid removal and selectivity of $\mathrm{TiO}_{2}$ coated photoanode. Chemosphere 73 (5), 854-858.

Hyun, C.K., Myong, J.Y., 2005. Characterization of natural organic matter in conventional water treatment processes for selection of treatment processes focused on DBPs control. Water Research 39 (19), 4779-4789.

Kim, D.H., Anderson, M.A., 1994. Photoelectrocatalytic degradation of formic acid using a porous $\mathrm{TiO}_{2}$ thin-film electrode. Environmental Science and Technology 28 (3), 479-483.

Kitis, M., Karanfil, T., Wigton, A., Kilduff, J.E., 2002. Probing reactivity of dissolved organic matter for disinfection byproduct formation using XAD-8 resin adsorption and ultrafiltration fractionation. Water Research 36 (15), 3834-3848.

Leenheer, J.A., Croue, J.P., Benjamin, M., Korshin, G.V., Hwang, C.J., Bruchet, A., Aiken, G.R., 2000. Comprehensive isolation of natural organic matter from water for special characterization and reactivity testing. ACS Symposium Series 761, 68-83.

Li, J., Liu, H.J., Zhao, X., Qu, J.H., Liu, R.P., Ru, J., 2008. Effect of preozonation on the characteristic transformation of fulvic acid and its subsequent trichloromethane formation potential: presence or absence of bicarbonate. Chemosphere 71 (9), 1639-1645.

Li, X.Z., Li, F.B., Fan, C.M., Sun, Y.P., 2002. Photoelectrocatalytic degradation of humic acid in aqueous solution using a $\mathrm{T}_{\mathrm{i}} / \mathrm{T}_{\mathrm{i}} \mathrm{O}_{2}$ mesh photoelectrode. Water Research 36 (9), 2215-2224.

Lin, L., Singer, P.C., 2003. Factors influencing the formation and relative distribution of haloacetic acids and trihalomethanes in drinking water. Environmental Science and Technology 37 (13), 2920-2928.

Nie, Y.L., Hu, C., Zhou, L., Qu, J.H., Wei, Q.S., Wang, D.S., 2010. Degradation characteristics of humic acid over iron oxides $/ \mathrm{Fe}^{0}$ core-shell nanoparticles with UVA $/ \mathrm{H}_{2} \mathrm{O}_{2}$. Journal of Hazardous Materials 173 (1-3), 474-479.

Patrica, A.M., Michael, J.P., Stephen, E.C., Qunhui, Z., Ksenija, N.D., George, R.A., 2002. A comparison of surface water natural organic matter in raw filtered water samples, $\mathrm{XAD}$, and reverse osmosis isolates. Water Research 36 (9), 2357-2371.

Pinhedo, L., Pelegrini, R., Bertazzoli, R., Motheo, A.J., 2005. Photoelectrochemical degradation of humic acid on a $\left(\mathrm{TiO}_{2}\right)_{0}$ ${ }_{7}\left(\mathrm{RuO}_{2}\right)_{0.3}$ dimensionally stable anode. Applied Catalysis $\mathrm{B}$ : Environmental 57 (2), 75-81.

Sanly, L., May, L., Rolando, F., Christopher, C., Ken, C., Mary, D., Rose, A., 2008a. Removal of humic acid using $\mathrm{TiO}_{2}$ photocatalytic process - Fractionation and molecular weight characterization studies. Chemosphere 72 (2), 263-271.

Sanly, L., May, L., Rolando, F., Christopher, C., Mary, D., Rose, A., 2008b. $\mathrm{TiO}_{2}$ photocatalysis of natural organic matter in surface water: impact on trihalomethane and haloacetic acid formation potential. Environmental Science and Technology 42 (16), 6218-6223. 
Shang, J., Li, W., Zhu, Y.F., 2003. Structure and photocatalytic characteristics of $\mathrm{TiO}_{2}$ film photocatalyst coated on stainless steel webnet. Journal of Molecular Catalysis A: Chemicstry 202 (1-2), 187-195.

Siva, S., Madjid, M., 2010. Effects of $\mathrm{UV} / \mathrm{H}_{2} \mathrm{O}_{2}$ advanced oxidation on chemical characteristics and chlorine reactivity of surface water natural organic matter. Water Research 44 (14), 4087-4096.

Swietlika, J., Sikorska, E., 2004. Application of fluorescence spectroscopy in the studies of natural organic matter fractions reactivity with chlorine dioxide and ozone. Water Research 38 (17), 3791-3799.

Tran, H., Scott, J., Chiang, K., Amal, R., 2006. Clarifying the role of silver deposits on titania for the photocatalytic mineralization of organic compounds. Journal of Photochemistry and Photobiology A: Chemistry 183 (1-2), 41-52.

U.S.EPA, 1990. Methods for the Determination of Organic Compounds in Drinking Water Supplement I. U.S.EPA, Cincinnati, $\mathrm{OH}$.

Valdemar, I., Marta, O., Armando, C., 2009. Comparative characterization of humic substances from the open ocean, estuarine water and fresh water. Organic Geochemistry 40 (9), 942-950.

Wen, C., Paul, W., Jerry, A.L., Karl, B., 2003. Fluorescence excitation-emission matrix regional integration to quantify spectra for dissolved organic matter. Environmental Science and Technology 37 (24), 5701-5710.

Xiao, S.H., Qu, J.H., Zhao, X., Liu, H.J., 2009. Electrochemical process combined with UV light irradiation for synergistic degradation of ammonium in chlorine-containing solutions. Water Research 43 (5), 1432-1440.

Xue, G., Liu, H.H., Chen, Q.Y., Hills, C., Tyrer, M., Innocent, F., 2011. Synergy between surface adsorption and photocatalysis during degradation of humic acid on $\mathrm{TiO}_{2} /$ activated carbon composites. Journal of Hazardous Materials 186 (1), 765-772.

Zhao, H., Liu, H.J., Hu, C.Z., Qu, J.H., 2009. Effect of aluminum speciation and structure characterization on preferential removal of disinfection byproduct precursors by aluminum hydroxide coagulation. Environmental Science and Technology 43 (13), 5067-5072. 